\title{
Современные подходы к профилактике пневмококковой инфекции
}

НИИ антимикробной химиотерапии Государственного образовательного учреждения высшего профессионального образования "Смоленская государственная медицинская академия Федерального агентства по здравоохранению и социальному развитию": 214019, Смоленск, ул. Кирова, 46А

\section{R.S.Kozlov, I.V.Andreeva, A.A.Martinovich \\ Modern approaches to prevention of pneumococcal diseases}

Key words: pneumococcal infection, pneumococcal vaccine, prevention, cost-effectiveness analysis, adverse events, resistant strains, unencapsulated antigens.

Ключевые слова: пневмококковая инфекция, пневмококковая вакцина, профилактика, анализ "стоимость-эффективность", нежелательные реакции, резистентные штаммы, некапсульные антигены.

В 1911 г. группа А.Райта разработала неочищенную цельноклеточную пневмококковую вакцину, которая была использована для иммунизации золотоискателей в Южной Африке [1]. Результаты показали некоторое снижение частоты пневмонии и летальных исходов от нее у вакцинированных лиц. После описания в 1923 г. М.Хейдельбергом и О.Эвери полисахаридного строения капсулы [2], уже в 1927 г. O.Шиманном и В.Каспером было установлено на животной модели, что введение пневмококковых полисахаридов стимулирует иммунитет [3]. Позднее к 1945 г. стало возможным проведение Ц.МакЛеодом 1-го успешного клинического исследования 4-валентной пневмококковой вакцины в военном лагеpe [4]. Через несколько месяцев началось исследование 6-валентной вакцины, которое, однако, вскоре было прекращено. Примерно в это же время в клиническую практику были внедрены антимикробные препараты, активные в отношении пневмококков, что привело к значительному улучшению исходов терапии. Высокая эффективность пенициллина в эти годы способствовала распространению мнения о том, что пневмококковые инфекции более не представляют клинической проблемы, вследствие чего имевшиеся 2 коммерческие 6-валентные вакцины к началу 1950-х гг. были сняты с производства.

Работы в области создания пневмококковых вакцин были приостановлены до клинического описания Р.Аустрианом и Дж.Голдом в 1964 г. 2000 случаев пневмококковой пневмонии в госпитале Kings County в Бруклине за период с 1952 по 1962 гг. [5]. Несмотря на повышение выживаемости пациентов с пневмококковыми пневмониями на фоне терапии пенициллином, летальность оставалась на уровне 25 \% при наличии бактериемии и была самой высокой у пожилых и лиц с хроническими заболеваниями. Непосредственным результатом этих исследований стало возобновление работ по разработке пневмококковых вакцин, которые были оценены в двойных слепых рандомизированных исследованиях среди золотоискателей в Южной Африке [6, 7]. Их резуль- таты подтвердили эффективность вакцинации для профилактики пневмонии, что привело к лицензированию в 1977 г. 14-валентной вакцины, содержащей 50 мкг капсулярного полисахарида каждого серотипа, в нее входящего. В 1981 г. она была заменена на 23-валентную, содержащую по 25 мкг очищенных капсулярных полисахаридных антигенов серотипов $1,2,3,4,5,6 \mathrm{~B}, 7 \mathrm{~F}, 8,9 \mathrm{~N}, 9 \mathrm{~V}, 10 \mathrm{~A}, 11 \mathrm{~A}, 12 \mathrm{~F}, 14,15 \mathrm{~B}$, $17 \mathrm{~F}, 18 \mathrm{C}, 19 \mathrm{~A}, 19 \mathrm{~F}, 20,22 \mathrm{~F}, 23 \mathrm{~F}, 33 \mathrm{~F}$, которая используется и в настоящее время. Пневмококки этих серотипов, по данным эпидемиологических исследований в различных странах мира, вызывают до $90 \%$ инвазивных форм инфекции у взрослых [8].

Пострегистрационные эпидемиологические исследования подтвердили эффективность пневмококковых полисахаридных вакцин для профилактики инвазивных форм инфекции (бактериемии и менингита) у пожилых людей и пациентов $\leq 2$ лет с определенными хроническими заболеваниями [9-12]. В крупном ретроспективном когортном исследовании, включавшем в себя данные 47365 пациентов в возрасте $\geq 65$ лет за 3 -летний период, было показано, что иммунизация пневмококковой полисахаридной вакциной значительно снижает риск возникновения пневмококковой бактериемии, но, в то же время, не влияет на частоту развития пневмонии как требующей, так и не требующей госпитализации, и на частоту госпитализации по поводу пневмонии у данной категории пациентов [13]. Только 1 исследование типа "случай-контроль" не показало эффективности вакцинации для профилактики бактериемии [14], возможно, вследствие ограничений исследования (малый размер выборки, неполная оценка иммунизационного анамнеза). В целом общая эффективность вакцинации для профилактики инвазивных форм пневмококковой инфекции у лиц $\geq 65$ лет составляет $75 \%$ [9], однако может снижаться с возрастом [12]. Полисахаридная вакцина обладает эффективностью от 65 до 84 \% в профилактике бактериемии и менингита у пациентов из групп высокого риска развития тяжелых форм пневмококко- 
вой инфекции с наличием определенной сопутствующей патологии (сахарный диабет, хронические заболевания дыхательной и сердечно-сосудистой систем, органическая аспления) [9].

Хотя применение полисахаридной пневмококковой вакцины и не предотвращает возникновения внебольничной пневмонии (ВП), данная тактика может облегчить течение заболевания и улучшить исходы. Так, по данным популяционного когортного исследования, у пациентов с ВП ( $n=3415$, средний возраст - 75 лет), предварительно вакцинированных пневмококковой вакциной, отмечалось снижение летальности или вероятности перевода в ОРИТ из-за тяжести течения пневмонии на $40 \%$ по сравнению с невакцинированными [15].

Еще в 1980-1990 гг. в США был проведен анализ показателя "стоимость-эффективность" вакцинации с использованием пневмококковой полисахаридной вакцины для профилактики бактериемии и менингита среди лиц в возрасте $\geq 65$ лет, который показал экономию в 8,27 долл. США на каждого иммунизированного [16]. В 2009 г. был опубликован метаанализ 11 исследований, в которых проводилась оценка показателя "стоимость-эффективность" вакцинации против пневмококковой инфекции у взрослых, который продемонстрировал, что данная тактика является экономически целесообразной [17]. На основании почти 30-летнего клинического опыта использования пневмококковые полисахаридные вакцины в целом считаются безопасными [8]. Тяжелые нежелательные реакции (например, анафилактические) регистрировались очень редко, а связь неврологических осложнений с введением пневмококковой вакцины (в частности, синдрома Гийена-Барре) не была доказана [18]. В метаанализе 9 рандомизированных контролируемых исследований эффективности пневмококковых вакцин нетяжелые местные реакции (например, болезненность в месте инъекции, эритема, отек) были отмечены примерно у 1/3 пациентов при отсутствии значительной лихорадки или анафилактоидных реакций [19]. Местные реакции обычно отмечаются в течение 48 ч после вакцинации и являются более частыми после ревакцинации. Так, например, среди лиц в возрасте от 50 до 74 лет, гиперемия и отек размером $\geq 10$ мм вокруг места инъекции были отмечены у $11 \%$ пациентов, получивших 1-ю инъекцию в течение $\geq 5$ лет, и только у $3 \%$ - при 1-й вакцинации [20]. Эти реакции не влияли на повседневную активность вакцинированных и имели среднюю продолжительность 3,6 дней до полного самостоятельного разрешения. Отек, боль и гиперемия в месте инъекции обычно связаны с более высокой концентрацией антикапсулярных антител до вакцинации, что приводит к формированию комплексов антиген-антитело в месте инъекции по типу феномена Артюса (III тип реакций гиперчувствительности) [20, 21]. Системные реакции средней степени тяжести (лихорадка, миалгия), а также более выраженные местные реакции (например, уплотнение) встречаются редко. Предварительные данные указывали на возможное транзиторное повышение репликации ВИЧ после введения пневмококковой вакцины [22, 23], однако клиническое значение этих наблюдений остается неясным.

Несмотря на отсутствие сообщений о нежелательных реакциях у новорожденных, матери которых были иммунизированы во время беременности, безопасность пневмококковых полисахаридных вакцин в период ранней беременности не исследовалась. Для защиты новорожденных в странах с высокой летальностью от пневмококковой инфекции в 1-е месяцы жизни исследовалась вакцинация женщин в последнем триместре беременности для определения возможности индукции трансплацентарного

Таблица 1

Рекомендации по использованию пневмококковой полисахаридной вакцины [8]

\begin{tabular}{|c|c|c|}
\hline Популяции, которым рекомендована вакцинация & $\begin{array}{l}\text { Доказательность }^{\text {рекомендации }}{ }^{1}\end{array}$ & Ревакцинация² \\
\hline Пациенты $\geq 65$ лет ${ }^{3}$ без иммунодефицита & A & $\begin{array}{l}\text { Рекомендована, если вакцина вводилась } \geq 5 \text { лет } \\
\text { и на момент введения пациенту было }<65 \text { лет }\end{array}$ \\
\hline \multicolumn{3}{|l|}{ Лица $\geq 2$ и < 65 лет с хроническими заболеваниями: } \\
\hline $\begin{array}{l}\text { сердечно-сосудистой системы (например, застойная сердечная } \\
\text { недостаточность); легких (например, ХОБЛ); сахарным диабетом; }\end{array}$ & A & Не рекомендуется \\
\hline алкоголизмом; печени (цирроз); шунтами ликворных путей & B & \\
\hline $\begin{array}{l}\text { Лица } \geq 2 \text { и < } 65 \text { лет с функциональной или анатомической аспленией } \\
\text { (например, с серповидноклеточной анемией, после спленэктомии) }\end{array}$ & A & $\begin{array}{l}\text { В возрасте > } 10 \text { лет рекомендована через } 5 \text { лет после } \\
\text { предыдущей дозы; в возрасте } \leq 10 \text { лет - рассмотреть } \\
\text { возможность ревакцинации через } 3 \text { года }\end{array}$ \\
\hline $\begin{array}{l}\text { Лица } \geq 2 \text { и < } 65 \text { лет, живущие в определенных условиях окружающей } \\
\text { среды или из особой популяции }\end{array}$ & C & Не рекомендуется \\
\hline $\begin{array}{l}\text { Лица с иммунодефицитными состояниями в возрасте } \geq 2 \text { лет, включая } \\
\text { пациентов: с ВИЧ-инфекцией; с лейкемией; с болезнью Ходжкина; } \\
\text { с множественной миеломой; с генерализованными злокачественными } \\
\text { новообразованиями; на иммуносупрессивной терапии (включая терапию } \\
\text { глюкокортикоидами); с хронической почечной недостаточностью; с нефро- } \\
\text { тическим синдромом; с срансплантатами органов и костного мозга }\end{array}$ & C & $\begin{array}{l}\text { Однократная ревакцинация, если прошло } \geq 5 \text { лет } \\
\text { после вакцинации. Если пациенту < } 10 \text { лет - } \\
\text { рассмотреть возможность ревакцинации через } 3 \text { года }\end{array}$ \\
\hline
\end{tabular}

Примечание: 1: A - достоверные эпидемиологические данные и значительные клинические преимущества вакцинации; В - умеренные доказательства эффективности вакцинации; C - эффективность вакцинации не доказана, однако высокий риск развития заболевания, потенциальные преимущества и безопасность вакцины создают основу для проведения иммунизации; ${ }^{2}$ - доказательность для всех рекомендаций по ревакцинации - C; ${ }^{3}$ - при неизвестном иммунизационном статусе этим группам рекомендована вакцинация. 
перехода антикапсулярных антител и увеличения концентрации специфического секреторного иммуноглобулина А в молозиве, что способствовало снижению адгезии пневмококков к клеткам эпителия ротоглотки [24]. В любом случае, женщины с высоким риском развития пневмококковой инфекции должны быть вакцинированы, по возможности, до беременности. Внутрикожное введение вакцины может вызвать серьезные местные реакции и поэтому не рекомендуется [8]. Единственным противопоказанием к введению пневмококковой полисахаридной вакцины является серьезная нежелательная реакция на предыдущую дозу вакцины [18].

Согласно рекомендациям Консультативного комитета по иммунизационной практике (Advisory Committee on Immunization Practices - ACIP), вакцинация рекомендуется лицам в возрасте $\geq 65$ лет с высоким риском развития пневмококковой инфекции, а также от 2 до 64 лет с наличием определенных хронических заболеваний (табл. 1).

Описанные вспышки пневмококковой пневмонии в домах длительного ухода, при которых только $5 \%$ резидентов были вакцинированы, подчеркивают необходимость иммунизации лиц в подобных учреждениях [25-27].

Лицам в возрасте $\geq 65$ лет рекомендовано введение 2-й дозы вакцины в случае, если 1-я была получена пациентом, по крайней мере, 5 лет назад. Пациентам с функциональной / анатомической аспленией, иммунодефицитными состояниями в возрасте $>10$ лет рекомендована 1-кратная ревакцинация не ранее чем через 5 лет после введения первой дозы. Кроме того, возможно проведение ревакцинации через 3 года детям в возрасте $\leq 10$ лет с высоким риском развития инфекции. Рутинная ревакцинация не рекомендуется остальным категориям пациентов. Необходимость введения дополнительных доз пневмококковой вакцины не доказана, а данных об их безопасности недостаточно, вследствие чего введение $\geq 3$ доз не рекомендуется [8].

Принимая во внимание, что инвазивные формы пневмококковой инфекции могут быть ранним проявлением ВИЧ-инфекции, а иммунный ответ на введение вакцины может быть более высоким на ее ранних стадиях, пациентам с числом CD4 лимфоцитов $\geq 200$ / мкл рекомендовано проведение иммунизации в возможно более короткие сроки после установления диагноза [28, 29]. Лицам, у которых число CD4 лимфоцитов $\leq 200$ / мкл, может быть предложена вакцинация, однако гуморальный ответ может оказаться более низким [30].

В настоящее время зарегистрированные или находящиеся на различных стадиях клинических ис-

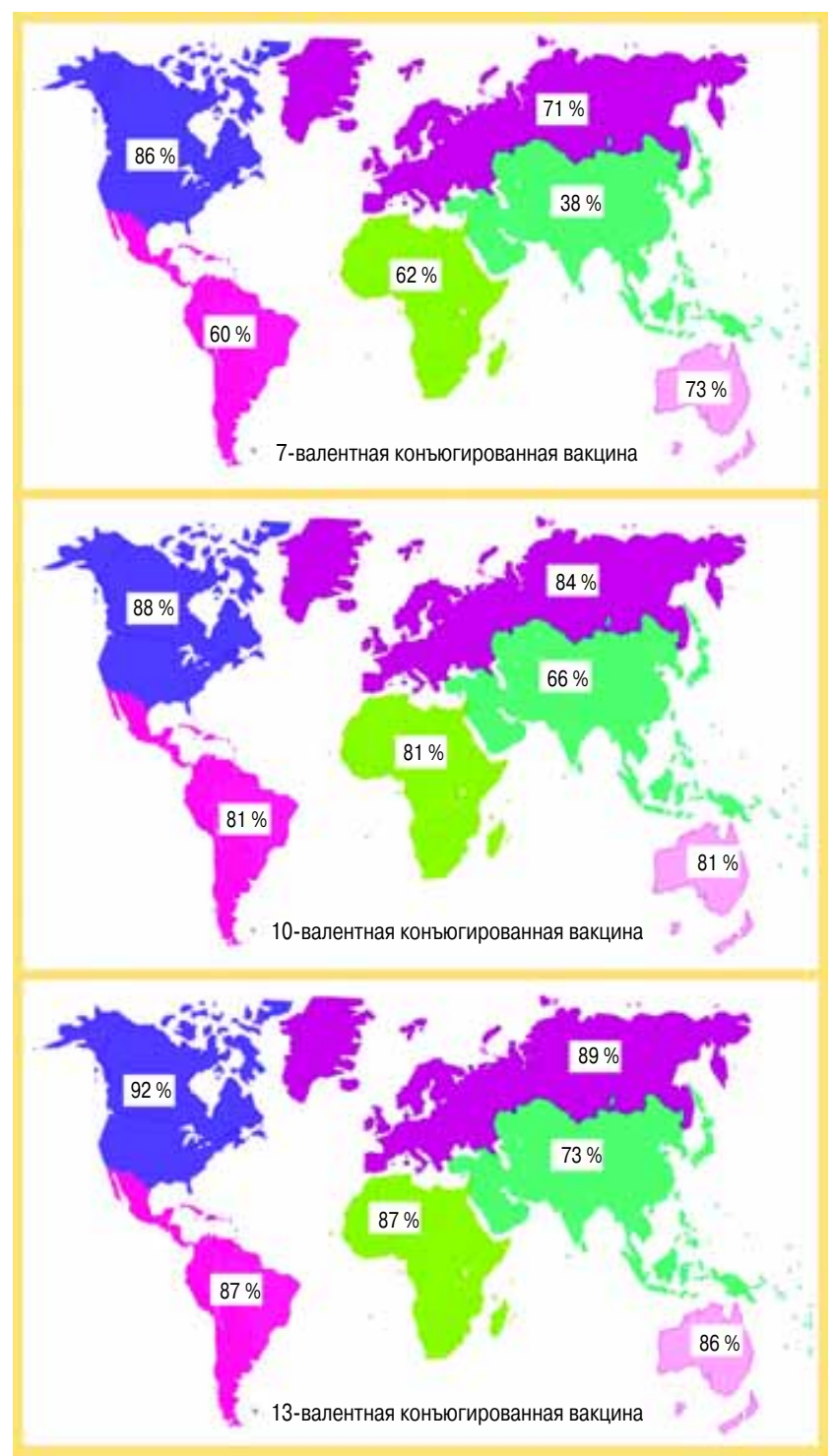

Рисунок. Доля случаев инвазивных форм пневмококковой инфекции у детей, предотвращаемых вакцинацией, при использовании 7-, 10- и 13-валентных пневмококковых вакцин в различных регионах мира

следований вакцины содержат от 7 до 13 серотипов. Характеристики основных вакцин представлены в табл. 2.

Следует учитывать существенные различия между серотипами, вызывающими инвазивные формы пневмококковой инфекции в разных частях мира. Так, согласно требованиям, предъявляемым к пневмококковым вакцинам в рамках Инициативы по авансированным обязательствам в закупках вакцин (Advance Market Commitments - AMC), серотипы вакцины должны перекрывать, как минимум, 60 \% серотипов, вызывающих инвазивные формы пневмо-

Таблица 2

Характеристики пневмококковых конъюгированных вакцин

\begin{tabular}{|l|l|l}
\hline Tип вакцины & Серотипы пневмококков, входящие в вакцину & \multicolumn{1}{c}{ Белковый носитель (конъюгат) } \\
\hline 7-валентная (PCV7) & $4,6 \mathrm{~B}, 9 \mathrm{~V}, 14,18,19 \mathrm{~F}, 23 \mathrm{~F}$ & Нетоксичный вариант дифтерийного токсина - белок CRM197 \\
\hline 10-валентная (PCV10) & $4,6 \mathrm{~B}, 9 \mathrm{~V}, 14,18,19 \mathrm{~F}, 23 \mathrm{~F}, 1,5,7 \mathrm{~F}$ & D-белок Haemophilus influenzae \\
\hline 13-валентная (PCV13) & $4,6 \mathrm{~B}, 9 \mathrm{~V}, 14,18,19 \mathrm{~F}, 23 \mathrm{~F}, 1,3,5,6 \mathrm{~A}, 7 \mathrm{~F}, 19 \mathrm{~A}$ & Нетоксичный вариант дифтерийного токсина - белок CRM197
\end{tabular}


кокковой инфекции, и должны включать 1, 5 и 14-й серотипы, как наиболее частые в странах, где мониторинг пневмококковой инфекции проводит Глобальный альянс по вакцинам и иммунизации (Global Alliance for Vaccines and Immunization - GAVI) [31]. Подобное перекрытие возможно только в том случае, если в состав вакцины входит $\geq 6$ серотипов [31].

На рисунке представлены данные по доле инвазивных форм пневмококковой инфекции у детей, предотвращаемых вакцинацией, при использовании 7-, 10- и 13-валентных конъюгированных пневмококковых вакцин в различных регионах мира [32]. Так, 7-валентная пневмококковая вакцина в наибольшей степени предотвращает инфекции в Северной Америке, в меньшей степени - на территории Европы, РФ, Южной Америки, Африки и Австралии и в наименьшей степени - в Азии. Это связано с тем, что PCV7 изначально синтезировалась на основании данных о распространенности отдельных серотипов на территории США и некоторых стран западной Европы. Это привело к тому, что в США вакцина перекрывает $86 \%$ штаммов, а на других континентах гораздо меньше: в Европе и Австралии 70 \%, Южной Америке и Африке $60 \%$, а в странах Азии $<40 \%$. PCV10 будет предотвращать > 80 \% случаев пневмококковой инфекции у детей во всех регионах, за исключением Азии (66 \%). Дополнительные антигены из серотипов $1,5,7 \mathrm{~F}$ повысят совпадение по циркулирующим серотипам с 86 до 88 \% в США и с 71 до $84 \%$ в Европе.

Внедрение 13-валентной вакцины повысит совпадение по серотипам пневмококков, входящим в вакцину, на 4-6 \% в Америке, Африке, Австралии и Европе, и, главное, перекрытие серотипов возрастет до $73 \%$ в Азии [32].

Первая 7-валентная конъюгированная вакцина (PCV7) была зарегистрирована в США в 2000 г. и в настоящее время разрешена к применению более чем в 90 странах мира, и более чем в 30 из них включена в Национальные календари профилактических прививок. Связывание полисахаридных антигенов с белковым носителем - нетоксичным мутантом дифтерийного токсина CRM197 - обеспечивает выраженный Т-зависимый иммунный ответ и долговременную иммунологическую память.

Результаты двойного слепого рандомизированного исследования PCV7 среди 37868 новорожденных и детей раннего возраста в Калифорнии показали общую эффективность вакцины для профилактики инвазивных форм пневмококковой инфекции, равную $97 \%$ [33].

Применение PCV7 в США снизило частоту пневмококковой бактериемии у детей 0-4 лет, вызванной входящими в состав вакцины антигенами пневмококков, с 81,9 до 1,7 на 100000 [34]. Несмотря на некоторое учащение бактериемии, вызванной не входящими в вакцину серотипами пневмококков (с 16,8 до 21,7), общее число случаев бактериемии снизилось в 4 раза - с 98,7 до 23,4 на 100000 населения [34]. Кроме воздействия на популяцию вакцинированных детей, использование PCV7 оказало положительное влияние и на другие категории пациентов: так, пневмония с бактериемией стала реже наблюдаться и у непривитых детей 5-15 лет (снижение частоты на $38 \%$ ), и у взрослых (на $47 \%$ - в возрасте 15-45 лет, на $20 \%$ - у 45-65-летних и на $36 \%$ - у лиц старше 65 лет). Влияние на показатели заболеваемости лиц старше 5 лет, не получивших вакцину, является результатом снижения передачи инфекции от привитых детей более младшего возраста, что, в свою очередь, обусловлено снижением носительства, - это т. н. "феномен коллективного иммунитета" [34].

Во всем мире за развитие большинства инфекций, вызванных пенициллинорезистентными штаммами пневмококков, отвечают 5 из 7 серотипов пневмококков, входящих в PCV7 (6B, 9V, 14, 19F и 23F) [35]. Наличие связи между серотипом и уровнем резистентности пневмококков позволяет предположить, что использование вакцины, наряду с выработкой иммунитета в отношении данного микроорганизма, способствует снижению частоты развития инфекций, вызванных резистентными штаммами. В ходе наблюдательного исследования Active Bacterial Core Surveillance за период с 1996 по 2004 гг. частота случаев инвазивных форм инфекции, вызванных нечувствительными к пенициллину и полирезистентными штаммами пневмококков, была наиболее высокой в 1999 г. и снизилась к 2004 г. (на $57 \%$ - с 6,3 до 2,7 случаев на 100000 и на $59 \%$ - с 4,1 до 1,7 случаев на 100000 соответственно). Также было отмечено снижение частоты развития инфекций, вызванных нечувствительными к пенициллину штаммами, среди детей в возрасте $<2$ лет (с 70,3 до 13,1 случаев на 100000 - на $81 \%$ ) и лиц в возрасте $\geq 65$ лет (с 16,4 до 8,4 случаев на 100000 - на $49 \%$ ). В то же время было отмечено повышение частоты выявления инфекций, вызванных серотипом 19А, не входящим в вакцину, с 2,0 до 8,3 случаев на 100000 среди детей < 2 лет. Таким образом, внедрение в клиническую практику пневмококковой конъюгированной вакцины привело к снижению частоты развития инвазивных форм пневмококковой инфекции, вызванных резистентными штаммами пневмококков, но к повышению частоты развития инфекций, вызванных резистентными штаммами, не входящими в вакцину [35].

Широкое использование 7-валентной пневмококковой конъюгированной вакцины также привело: 1) к значительному снижению частоты носительства серотипов пневмококков, входящих в вакцину; 2) к снижению частоты носительства пневмококков с высоким уровнем резистентности к пенициллину среди вакцинированных детей [36].

Защитная эффективность PCV7 в отношении острого среднего отита (ОСО) является относительно невысокой. В рамках исследования, проведенного в Финляндии, применение PCV7 привело к снижению частоты ОСО с подтвержденной пневмококковой этиологией на 34 \%; частоты ОСО, вызванного серотипами пневмококков, входящими в состав вакцины, на 57 \%, однако снижение частоты всех случаев ОСО, независимо от этиологии, составило лишь $6 \%$ [37]. 
В 2009 г. более чем в 40 странах, включая страны ЕС, была зарегистрирована 10-валентная конъюгированная пневмококковая вакцина (PCV10), в которой полисахаридные антигены связываются с носителем (D-белок H. influenzae), что обеспечивает выраженный Т-зависимый иммунный ответ и долговременную иммунологическую память, с одной стороны, и дополнительную защиту от нетипируемых штаммов $H$. influenzae - с другой [38]. Новые вакцинные серотипы 1, 5 и 7F в PCV10 являются высоко инвазивными, вызывают вспышки и тяжелое течение заболевания у детей младшего возраста $[39,40]$.

Отличительной особенностью PCV10 от PCV7, помимо большей доли инвазивных форм инфекции, предотвращаемых вакцинацией, является и эффективность PCV10 в профилактике ОСО. Так, по данным исследования РОЕТ (Pneumococcal Otitis Media Efficacy Trial), отмечалось статистически достоверное снижение частоты ОСО в группе, получивших пневмококковую вакцину, на 34 \%; эффективность против вакцинных серотипов пневмококка, вызывающих ОСО, составила $58 \%$; эффективность против любых других серотипов пневмококков-возбудителей ОСО - 53 \% и эффективность для ОСО, вызванного нетипируемыми штаммами гемофильной палочки, $-35 \%$ [41].

Зарегистрированные к настоящему времени конъюгированные пневмококковые вакцины разрешены для применения у детей с самого раннего возраста: PCV7 - с 2 мес., PCV10 - с 6 нед. Курс первичной вакцинации зависит от сроков начала введения вакцины (рекомендуемый курс состоит из 3 доз, если вакцинация началась в 1-м полугодии жизни, и 2 доз - если во 2-м, вводимых внутримышечно). Бустерное введение вакцины рекомендуется на 2-м году жизни. Схемы введения 7- и 10-валентных конъюгированных пневмококковых вакцин представлены в табл. 3.

Результаты клинических и пострегистрационных эпидемиологических исследований показали, что пневмококковые конъюгированные вакцины являются безопасными [44-47]. Так, благоприятный профиль безопасности PCV7 до лицензирования был установлен в 5 клинических исследованиях с участием более чем 18000 детей [45]. Крупнейшее пострегистрационное исследование, посвященное безопасности PCV7, проводилось в США и включало в себя наблюдение за более чем 162000 пациентов [45]. При проведении анализа не было выявлено каких-либо новых проблем, связанных с безопасностью вакцины, которые могли бы изменить текущее соотношение "риск-польза" для PCV7.

Результаты международного экономического анализа эффективности вакцинации пневмококковой конъюгированной вакциной у детей младшего возраста (72 страны, 2005 г.) свидетельствуют об экономической целесообразности вакцинации и существенном снижении детской смертности в развивающихся странах [48]. В исследуемых развивающихся странах прививка против пневмококковой инфекции была проведена с тем же охватом детского населения, что и вакцинация АКДС. При этом были предотвращены 262000 смертей детей в возрасте от 3 до 29 мес. в год, что, следовательно, сохраняет 8,34 млн лет жизни с учетом утраты здоровья ежегодно (Disability Adjusted Life Expectancy - DALYs). Если бы вакцинировали всех детей, то стало бы возможным предупреждение до 407000 детских смертей ежегодно. Учитывая, что стоимость вакцины $\sim 5$ долл. США, общие затраты на вакцинацию составляют 838 млн долл. США. При сопоставлении национального валового продукта, приходящегося на душу населения, с годами сохраненной трудоспособности,

Схемы введения 7- и 10-валентных Таблиц 3

\begin{tabular}{|c|c|c|c|}
\hline \multirow[t]{2}{*}{ Вакцина } & \multirow[t]{2}{*}{ Показания } & \multicolumn{2}{|c|}{ Схема введения } \\
\hline & & Первичная вакцинация & Бустер / повторная вакцинация \\
\hline \multirow[t]{4}{*}{ 7-валентная } & $\begin{array}{l}\text { Профилактика пневмококковых инфекций } \\
\text { у детей от } 2 \text { мес. до } 5 \text { лет }\end{array}$ & $\begin{array}{l}\text { 2-6 мес.: } 3 \text { дозы (0,5 мл) } \\
\text { с интервалом между } \\
\text { введениями не менее } 1 \text { мес. } \\
\text { (рекомендуемая схема: } \\
\text { 2-4-6 мес.) }\end{array}$ & $\begin{array}{l}\text { Введение бустерной дозы рекомендуется } \\
\text { на 2-м году жизни, предпочтительно } \\
\text { в возрасте } 12-15 \text { мес. }\end{array}$ \\
\hline & & $\begin{array}{l}\text { 7-11 мес.: } 2 \text { дозы (0,5 мл) } \\
\text { с интервалом не менее } 1 \text { мес. }\end{array}$ & $\begin{array}{l}\text { Бустерная доза вакцины вводится } \\
\text { на 2-м году жизни }\end{array}$ \\
\hline & & $\begin{array}{l}\text { 12-23 мес.: } 2 \text { дозы (0,5 мл) } \\
\text { с интервалом не менее } 2 \text { мес. }\end{array}$ & \\
\hline & & $\begin{array}{l}\text { 2-5 лет: } 1 \text { доза (0,5 мл) } \\
\text { однократно }\end{array}$ & \\
\hline \multirow[t]{3}{*}{ 10-валентная } & $\begin{array}{l}\text { Активная иммунизация против серотипов } 1,4,5,6 \mathrm{~B}, 7 \mathrm{~F}, \\
9 \mathrm{~V}, 14,18 \mathrm{C}, 19 \mathrm{~F} \text { и } 23 \mathrm{~F} \text { и инвазивных форм инфекции, } \\
\text { вызываемых этими серотипами (сепсис, менингит, } \\
\text { пневмония с бактериемией, эмпиема плевры } \\
\text { и бактериемия), детей от } 6 \text { нед. до } 2 \text { лет }\end{array}$ & $\begin{array}{l}6 \text { нед. - } 6 \text { мес.: } 3 \text { дозы (0,5 мл) } \\
\text { с интервалом не менее } 1 \text { мес. } \\
\text { (рекомендуемая схема - } \\
\text { 2-4-6 мес.) }\end{array}$ & $\begin{array}{l}\text { Бустерная доза рекомендуется, как } \\
\text { минимум, через } 6 \text { мес. после введения } \\
\text { последней дозы первичного курса вак- } \\
\text { цинации, предпочтительно в возрасте } \\
12-15 \text { мес. }\end{array}$ \\
\hline & & $\begin{array}{l}\text { 7-11 мес.: } 2 \text { дозы (0,5 мл) } \\
\text { с интервалом не менее } 1 \text { мес. }\end{array}$ & $\begin{array}{l}\text { 3-я доза вакцины вводится на 2-м году } \\
\text { жизни с интервалом между дозами, } \\
\text { как минимум, } 6 \text { мес. }\end{array}$ \\
\hline & & $\begin{array}{l}\text { 12-23 мес.: } 2 \text { дозы (0,5 мл) } \\
\text { с интервалом не менее } 2 \text { мес. }\end{array}$ & \\
\hline
\end{tabular}


обеспеченной вакцинацией, выяснилось, что вакцинация по такой цене будет экономически эффективной в 68 странах из 72 [48].

Следует отметить, что в практике применения пневмококковых вакцин существует 2 основных спорных момента [32]. Первый - обсуждает насколько полно вакцина перекрывает серотипы, циркулирующие в каждом конкретном регионе (стране), и как это может отразиться на эффективности вакцинации. В связи с этим перед широким использованием конъюгированных вакцин, в частности в Российской Федерации, необходимо проведение многоцентровых эпидемиологических исследований по определению преобладающих серотипов пневмококков, вызывающих инвазивные и неинвазивные формы инфекции в различных регионах. Только такие результаты позволят определить возможную эффективность вакцин с точки зрения принципов доказательной медицины.

Вторым моментом является изменение серотипного состава пневмококков уже после начала массовой иммунизации. Как отмечалось ранее, на фоне снижения заболеваемости инфекциями, вызываемыми вакцинными серотипами, отмечается возрастание роли "невакцинных" серотипов (т. н. "эффект замещения"). Эффект замещения с биологической точки зрения является признаком эффективности вакцинации. На сегодняшний день этот прирост мало влияет на общее снижение заболеваемости, однако, с одной стороны, существует риск роста заболеваемости за счет невакцинных серотипов пневмококка в будущем и, с другой стороны, вызывает беспокойство распространение серотипов со множественной лекарственной резистентностью. Наибольшие опасения на данный момент вызывает распространение серотипа 19А, который является более резистентным к антибиотикам, а течение инфекций, вызванных данным серотипом, более агрессивно [49]. Наиболее логичным решением данной проблемы является изменение состава вакцины в зависимости от меняющегося серотипного состава [32]. Так, упомянутый серотип 19А входит в состав 13-валентной конъюгированной пневмококковой вакцины.

Альтернативным подходом к профилактике пневмококковых инфекций является разработка вакцин к некапсульным антигенам - общим для всех пневмококковых серотипов. Подобными антигенами были нейраминидаза, аутолизин, пневмолизин, пневмококковые поверхностные протеины А и С (РspA и РspC), пневмококковый поверхностный адгезин A (PsaA) [50-53]. Эти белки теоретически могут обеспечивать не только защиту против всех пневмококковых серотипов, но и приводить к стимуляции Т-зависимого ответа с развитием иммунологической памяти. До настоящего времени, только пневмолизин, PspA и PsaC были широко исследованы для использования в вакцинах. Интраназальное введение PspA мышам не только приводило к выработке местного и системного иммунного ответа, предотвращая колонизацию пневмококками, но и обеспечивало защиту от системных инфекций после внутривен- ного, интратрахеального и интраперитонеального введения живой культуры [54]. Вакцина, состоящая из живого рекомбинантного штамма Salmonella typhimurium, экспрессировавшего пневмококковый PspA, колонизовала лимфоидную ткань кишечника, селезенку и печень мышей после пероральной иммунизации и приводила к стимуляции выработки сывороточных и локальных анти-РspA антител, обеспечивая защиту против вирулентных в отношении мышей штаммов Streptococcus pneumoniae [55].

Потенциальные преимущества ДНК-вакцин являются особенно привлекательными в развивающихся странах, где существует необходимость в вакцинах с невысокой стоимостью, которые не требуют соблюдения холодовой цепи. Результаты предварительной работы с пневмококковой ДНК-вакциной показали, что иммунизация мышей плазмидами, экспрессирующими PspA, стимулировала значительный иммунный ответ с обеспечением некоторой защиты против внутривенного введения S. pneumoniae 3-го серотипа [56].

Таким образом, эффективные пути специфической профилактики инвазивных форм пневмококковой инфекции у взрослых и детей существуют.

Стратегическая консультативная группа экспертов по иммунизации (Strategic Advisory Group of Experts on Immunization - SAGE) при ВОЗ выпустила рекомендации о приоритетном значении предупреждения пневмококковой инфекции во всем мире. ВО3 рекомендует в приоритетном порядке включать конъюгированные пневмококковые вакцины в Национальные календари профилактических прививок.

\section{Литература}

1. Wright A.E., Morgan W.P., Cantab M.B. et al. Observation on prophylactic inoculations against pneumococcus infection, and on the results which have been achieved by it. Lancet 1914; 1: 87-95.

2. Heidelberg M., Avery O.T. The soluble specific substance of pneumococcus. J. Exp. Med. 1923; 38: 73-79.

3. Schiemann O., Casper $W$. Sind die spezifisch pracipitablen Substanzen der 3 Pneumokokkentypen Haptene? Z. Hyg. Infektionskr. 1927; 108: 220-257.

4. MacLeod C.M., Hodges R.G., Heidelberg M. et al. Prevention of pneumococcal pneumonia by immunization with specific capsular polysaccharides. J. Exp. Med. 1945; 82: 445-465.

5. Austrian R., Gold J. Pneumococcal bacteremia with a special reference to bacteremic pneumococcal pneumonia. Ann. Intern. Med. 1964; 60: 759-776.

6. Austrian R., Douglas R.M., Schiffman G. et al. Prevention of pneumococcal pneumonia by vaccination. Trans. Assoc. Am. Physicians 1976; 89: 184-189.

7. Smit P., Oberholzer D., Hayden-Smith S. et al. Protective efficacy of pneumococcal polysaccharide vaccines. J.A.M.A. 1977; 238: 2613-2616.

8. Advisory Committee on Immunization Practices. Prevention of pneumococcal diseases: recommendations of the advisory committee on immunization practices. Mortal. Morbid. Wkly Rep. 1997; 46: 1-24.

9. Butler J.C., Breiman R.F., Campbell J.F. et al. Polysaccharide pneumococcal vaccine efficacy: an evaluation of current recommendations. J.A.M.A. 1993; 270: 1826-1831. 
10. Preventing pneumococcal bacteremia at patients at risk. Results of a matched case-control study. Arch. Intern. Med. 1995; 155: 2336-2340.

11. Sims R.V., Steinmann W.C., McConville J.H. et al. The clinical effectiveness of pneumococcal vaccine in the elderly. Ann. Intern. Med. 1988; 108: 653-657.

12. Shapiro E.D., Berg A.T., Austrian R. et al. The protective efficacy of polyvalent pneumococcal polysaccharide vaccine. N. Engl. J. Med. 1991; 325: 1453-1460.

13. Jackson L.A., Neuzil K.M., Yu O. et al. Effectiveness of pneumococcal polysaccharide vaccine in older adults. $\mathrm{N}$. Engl. J. Med. 2003; 348: 1747-1755.

14. Forrester H.L., Jahningen D.W., LaForce F.M. Inefficacy of pneumococcal vaccine in a high-risk population. Am. J. Med. 1987; 83: 425-430.

15. Johnstone J., Marrie T.J., Eurich D.T. et al. Effect of pneumococcal vaccination in hospitalized adults with community-acquired pneumonia. Arch. Intern. Med. 2007; 167 (18): 1938-1943.

16. Sisk J.E., Moskowitz A.J., Whang W. et al. Cost-effectiveness of vaccination against pneumococcal bacteremia among elderly people. J.A.M.A. 1997; 278: 1333-1339.

17. Ogilvie I., Khoury A.E., Cui Y. et al Cost-effectiveness of pneumococcal polysaccharide vaccination in adults: a systematic review of conclusions and assumptions. Vaccine 2009; 27 (36): 4891-4904.

18. Fedson D.S., Musher D.M., Eskola J. Pneumococcal vaccine. In: Plotkin S.A., Orenstein W.A., Vaccines $3^{\text {rd }}$ ed. Philadelphia: W.B. Saunders; 1999. 553-607.

19. Fine M.J., Smith M.A., Carson C.A. et al. Efficacy of pneumococcal vaccination in adults: a meta-analysis of randomized controlled trials. Arch. Intern. Med. 1994; 154: 2666-2677.

20. Jackson L.A., Benson P., Sneller V.-P. et al. Safety of revaccination with pneumococcal polysaccharide vaccine. J.A.M.A. 1999; 281: 243-248.

21. Sankilampi U., Honkanen P.O., Bloigu A. et al. Persistence of antibodies to pneumococcal capsular polysaccharide vaccine in patients in the elderly. J. Infect. Dis. 1997; 176: 1100-1104.

22. Brichacek B., Swindells S., Janoff E.N. et al. Increased plasma human immunodeficiency virus type 1 burden following antigenic challenge with pneumococcal vaccine. J. Infect. Dis. 1996; 174: 1191-1199.

23. Katzenstein T.L., Gerstoft J., Nielsen H. Assessments of plasma HIV RNA and CD4 cell counts after combined Pneumovax $^{\circledR}$ and tetanus toxoid vaccination. Scand. J. Infect. Dis. 1996; 28: 239-241.

24. O'Dempsey T.J.D., McArdle T., Ceesay S.J. et al. Immunization with a pneumococcal capsular polysaccharide vaccine during pregnancy. Vaccine 1996; 14: 963-970.

25. Nuorti J.P., Butler J.C., Crutcher J.M. et al. An outbreak of pneumonia and bacteremia due to multidrug-resistant Streptococcus pneumoniae among unvaccinated nursing home residents. N. Engl. J. Med. 1998; 338: 1861-1868.

26. Centers for Disease Control and Prevention. Outbreaks of pneumococcal pneumonia among unvaccinated residents in chronic-care facilities - Massachusetts, October 1995, Oklahoma, February 1996, and Maryland, May-June 1996. Mortal. Morbid. Wkly Rep. 1997; 46: 60-62.

27. Fiore A.E., Iverson C., Messmer T. et al. Outbreak of pneumonia in a long-term care facility: antecedent human parainfluenza virus 1 infection may predispose to bacterial pneumonia. J. Am. Geriatr. Soc. 1998; 46: 1112-1117.

28. Rodriguez-Barradas M.C., Tharapel R.A., Groover J.E. et al. Colonization by Streptococcus pneumoniae among human immunodeficiency virus-infected adults: prevalence of antibiotic resistance, impact of immunization, and characterization by polymerase chain reaction with BOX primers of isolates from persistent S. pneumoniae carriers. J. Infect. Dis. 1997; 175: 590-597.

29. USPHS / IDSA Prevention of Opportunistic Infections Working Group. Prevention of opportunistic infections in persons infected with human immunodeficiency virus. Ann Intern Med 1997; 127: 922-946.

30. Rodriguez-Barradas M.C., Musher D.M., Kahart C., et al. Antibody to capsular polysaccharides of Streptococcus pneumoniae after vaccination of human immunodeficiency virus-infected subjects with 23 -valent pneumococcal vaccine. J. Infect. Dis. 1992; 165: 553-556.

31. Target Product Profile and Technical Requirements. Pretender Meeting Pneumococcal Vaccines under the AMC, UNICEF Supply Division, Copenhagen, 26 Aug. 2009. Copenhagen; 2009.

32. GAVI Alliance. Pneumococcal Vaccines: Suppliers, pipelines, and availability: 4th Annual network conference, 9-10 November 2006.

33. Black S., Shinefeld H., Fireman B. et al. Efficacy, safety and immunogenecity of heptavalent pneumococcal conjugate vaccine in children. Northern California Kaiser Permanente Vaccine Study Group. Pediatr. Infect. Dis. J. 2000; 19: 187-195.

34. Centers for Disease Control and Prevention (CDC). Invasive pneumococcal disease in children 5 years after conjugate vaccine introduction - eight states, 1998-2005. Mortal. Morbid. Wkly Rep. 2008; 57 (6): 144-148.

35. Kyaw M.H., Lynfield R., Schaffner W. et al. Effect of introduction of the pneumococcal conjugate vaccine on drugresistant Streptococcus pneumoniae. N. Engl. J. Med. 2006; 354 (14): 1455-1463.

36. Grivea I.N., Panagiotou M., Tsantouli A.G. et al. Impact of heptavalent pneumococcal conjugate vaccine on nasopharyngeal carriage of penicillin-resistant Streptococcus pneumoniae among day-care center attendees in central Greece. Pediatr. Infect. Dis. J. 2008; 27 (6): 519-525.

37. Eskola J., Kilpi T., Palmu A. et al. Efficacy of a pneumococcal conjugate vaccine against acute otitis media. N. Engl. J. Med. 2001; 344 (6): 403-409.

38. Wysocki J., Galaj A., Omecaca F. et al. Data presented at ISPPD 2008. Pneumococcal Regional Serotype Distribution for Pneumococcal AMC TPP, PneumoADIP Report, November 2008.

39. Hausdorff W.P. The roles of pneumococcal serotypes 1 and 5 in paediatric invasive disease. Vaccine 2007; 25 (13): 2406-2412.

40. Pneumococcal Regional Serotype Distribution for Pneumococcal AMC TPP, PneumoADIP Report, November 2008. Available at: www.vaccineamc.org/files/TTP_Codebook.pdf

41. Prymula R., Peeters P., Chrobok V. et al. Pneumococcal capsular polysaccharides conjugated to protein $\mathrm{D}$ for prevention of acute otitis media caused by both Streptococcus pneumoniae and non-typable Haemophilus influenzae: a randomised double-blind efficacy study. Lancet 2006; 367 (9512): 740-748.

42. Prevnar ${ }^{\circledR}$. Pneumococcal 7-valent Conjugate Vaccine (Diphtheria CRM197 Protein). Product monograph. Manufactured by: Wyeth Pharmaceuticals. Available from: http://www.wyeth.ca/en/products/Product\%20Monograph s\%20PDFs/Prevnar_PM_Dec_22_2008_sub_Jan_8_2009. $p d f$

43. Synflorix ${ }^{\circledR}$. Pneumococcal polysaccharide conjugate vaccine, 10-valent adsorbed. Approved Product Information. 
GlaxoSmithKline Australia Pty Ltd. Available from: http://www.gsk.com.au/resources.ashx/vaccineproductschilddataproinfo/151/FileName/F95603879DCA33D25B69CF2D 7FE45D0D/PI_Synflorix.pdf

44. Rennels M.B., Edwards K.M., Keyserling H.L. et al. Safety and immunogenicity of heptavalent pneumococcal conjugated to CRM197 in United States infants. Pediatrics 1998; 101 (4, Pt 1): 604-611.

45. Center K.J., Strauss A. Safety experience with heptavalent pneumococcal CRM197-conjugate vaccine (Prevenar) since vaccine introduction. Vaccine 2009; 27 (25-26): 3281-3284

46. Destefano F., Pfeifer D., Nohynek $H$. Safety profile of pneumococcal conjugate vaccines: systematic review of pre- and post-licensure data. Bull. Wld Hlth Org. 2008; 86 (5): 373-380.

47. Chevallier B., Vesikari T., Brzostek J. et al. Safety and reactogenicity of the 10-valent pneumococcal non-typeable Haemophilus influenzae protein $\mathrm{D}$ conjugate vaccine (PHiD-CV) when coadministered with routine childhood vaccines. Pediatr. Infect. Dis. J. 2009; 28 (4, Suppl.): S109$\mathrm{S} 118$.

48. Sinha A., Levine O., Knoll M.D. et al. Cost-effectiveness of pneumococcal conjugate vaccination in the prevention of child mortality: an international economic analysis. Lancet 2007; 369 (9559): 389-396.

49. Ongkasuwan J., Valdez T.A., Hulten K.G. et al. Pneumococcal mastoiditis in children and the emergence of multidrug-resistant serotype 19A isolates. Pediatrics 2008; 122 (1): $34-39$.

50. Sampson J.S., Furlow Z., Whitney A.M. et al. Limited diversity of Streptococcus pneumoniae psaA among pneumococcal vaccine serotypes. Infect. and Immun. 1997; 65: 1967-1971.
51. Lock R.A., Paton J.C., Hansman D. Comparative efficacy of pneumococcal neuraminidase and pneumolysin as immunogens protective against Streptococcus pneumoniae infection. Microb. Pathogen. 1988; 5: 461-467.

52. Briles D.E., Hollingshead S.K., Swiatlo E. et al. PspA and PspC: Their potential for use as pneumococcal vaccines. Microb. Drug. Resist. 1997; 3: 401-408.

53. McDaniel L.S., Sheffield J.S., Delucchi P. et al. PspA, a surface protein of Streptococcus pneumoniae, is capable of eliciting protection against pneumococci of more than one capsular serotype. Infect. Immun. 1991; 59: 222-228.

54. Wu H.-Y., Nahm M.H., Guo Y. et al. Intranasal immunization of mice with PspA (pneumococcal surface protein A) can prevent intranasal carriage, pulmonary infection and sepsis with Streptococcus pneumoniae. J. Infect. Dis. 1997; 175: 839-846.

55. Nayak A.R., Tinge S.A., Tart R.C. et al. A live recombinant virulent oral Salmonella vaccine expressing pneumococcal surface protein A induces protective responses against Streptococcus pneumoniae. Infect. and Immun. 1998; 66: 3744-3751.

56. McDaniel L.S., Loechel F., Benedict C. et al. Immunization with a plasmid expressing pneumococcal surface protein A (PspA) can elicit protection against fatal infection with Streptococcus pneumoniae. Gene Ther. 1997; 4: 375-377.

\section{Информация об авторах}

Козлов Роман Сергеевич - д. м. н., проф., директор НИИАХ; тел.: (8412) 45-06-02, 45-06-03; факс: (8412) 45-06-02, 45-06-03 (доб. 123); e-mail: roman@antibiotic.ru

Андреева Ирина Вениаминовна - к. м. н., ст. науч. сотрудник НИИАХ; тел.: (8412) 61-13-01 (доб. 126); факс: (8412) 45-06-02, 45-06-03 (доб. 123); e-mail: andreeva@antibiotic.ru

Мартинович Алексей Александрович - к. м. н., мл. науч. сотрудник НИИАХ; тел.: (8412) 45-06-02, 45-06-03 (доб. 113); факс: (8412) 45-06-02, 45-06-03 (доб. 123); e-mail: alex.martinovich@antibiotic.ru

Поступила 29.07.10 (с) Коллектив авторов, 2010 удК [616.98:579.862]-084 